\title{
Can Momentum Factors be used to Enhance Accounting Information based Fundamental Analysis in Explaining Stock Price Movements? ${ }^{1}$
}

\author{
KiHoon Jimmy Hong and Eliza Wu ${ }^{\mathrm{a}, 2}$

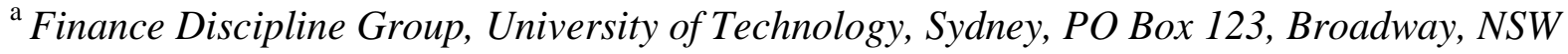 \\ 2007, Australia
}

\begin{abstract}
This paper provides new empirical evidence that price-based momentum indicator variables can enhance the ability of accounting variables in explaining cross-sectional stock returns. We apply both OLS and state-space modelling to a sample of firms included in the Russell 3000 index over the period from 1999-2012 to compare the roles of the two main types of information typically used by equity investors. Empirical results reveal the importance of accounting variables over longer term horizons for particularly, small-cap stocks. Momentum variables are shown to be important in the shorter term horizons. This result remains robust to alternative methodologies used.
\end{abstract}

JEL classification: G12; G14

Keywords: Stock Returns, Fundamental Analysis, Momentum, State Space Model

\footnotetext{
${ }^{1}$ We would like to thank Terry Walter, Steve Satchell and YongWoong Lee for useful discussions. We gratefully acknowledge financial support from the Accounting \& Finance Association of Australia and New Zealand (AFAANZ). All errors remain our own.

${ }^{2}$ Corresponding author. Tel: +495147777

E-mail address: Eliza.Wu@uts.edu.au
} 


\section{Introduction}

In this paper, we investigate whether stock price based momentum analysis (also known as time series momentum analysis in Moskowitz, Ooi and Pedersen, 2012), can enhance the effectiveness of fundamental analysis in explaining stock price movements (SPM hereafter). We contribute new evidence to the on-going debate on whether price-based or fundamental-based equity valuation is more useful for equity analysts by using a state space modelling approach to avoid potential omitted variable bias which has long plagued the comparison of these two alternative approaches to equity valuation. Our model includes a latent variable, which represents an unobservable market wide common factor. We also explore if there exists a firm size effect in the relative importance of accounting information and momentum indicators for explaining SPM.

We have three major empirical findings. First, we show that combining both momentum and fundamental analysis can better explain SPM, compared to the cases where momentum or fundamental analysis is employed independently. This result has important implications for both academics and practitioners trying to understand stock price behaviour. Second, we uncover that the unobserved common factor provides statistically significant explanatory power for SPM. This implies that the results of Duffie et al. (2009), which find the presence of statistically significant common latent factors in estimating corporate default probabilities, could also apply to equity markets. Third, we find that there exists a significant size effect in the relative importance of the momentum and fundamental variables.

Explaining and predicting SPM has for a long time intrigued both academics and practitioners. There are two long-standing approaches to valuing stocks, fundamental and technical analysis. Fundamental analysts primarily use accounting information to derive a company's intrinsic value based on its earnings, dividends, investment opportunities, cost of 
capital and so forth. On the other hand, technical analysts focus mainly on stock's own historical prices and returns. It is commonly accepted that technical analysis performs better in the short term while fundamental analysis is often believed to provide better estimates on long term intrinsic values (see for example, Taylor and Allen, 1992, Lui and Mole, 1998 and Amini et al., 2013).

Since Levy (1967) first revealed that trading strategies based on previous stock prices can be profitable, numerous studies have subsequently found support for weak-form market efficiency (See for example, Grossman and Stiglitz, 1980 and Alexeeva and Tapon, 2011). Weak-form market efficiency implies that existing prices reflect all the information contained in past public news (including past prices). Our study does not explicitly test market efficiency because it is out of this paper's research scope but it is conceptually consistent with these studies supporting the weak-form Efficient Market Hypothesis.

Most of the existing literature has focused on one or the other aspect of SPM but not both. This may be the fundamental reason why cross-sectional stock returns cannot be satisfactorily explained. The market price and its behavior over time provide meaningful information not provided by the accounting information that determines the intrinsic value of a stock. Price histories can indicate the psychology of the market better than firm fundamental factors and provide information regarding the sentiment of other participants in the market. Thus, fundamental and technical analysis that are based on the information contained in firms' accounting numbers and stock's own past market information respectively, should ideally be considered together in explaining SPM. Surprisingly, there has been little attention placed on understanding their complementary roles and there remains scant evidence on their joint ability to determine SPM.

For example, Ou and Penman (1989) performed a financial statement analysis that combined a large set of financial statement items into one summary measure and showed that 
it could indicate the direction of stock returns in the near term. On the other hand, a comprehensive study by Brock, Lakonishok and LeBaron (1992) analysed 26 technical trading rules using daily stock prices from the Dow Jones Industrial Average Index and found that all of the price-based strategies outperformed the market.

While we note that technical analysis is a very broad concept and is hard to give a clear and concrete definition, momentum analysis is a type of technical analysis that can be clearly defined (See Hong and Satchell, 2012). Therefore in this paper, we consider fundamental and technical analysis jointly to comprehensively investigate the effect of both sets of information on SPM. Our work is close to that of Taylor and Allen (1992), Bollinger (2005) and Bettman et al. (2009). However, we differentiate our study from earlier attempts by considering a richer set of momentum indicators capturing price-based information over different time horizons alongside accounting variables. Importantly, we contribute a more accurate comparison of the explanatory power provided by accounting information and price-based momentum indicators for stock price variations by accounting for common unobservable factors that may also influence stock prices.

For large companies that have many equity analysts following their stock, most of the fundamental information should be incorporated into past stock prices. For small companies that do not have many analysts following the company, there exists greater information asymmetry with respect to the company's news. If it is good news that would push the stock price up, the executives of the company would actively spread the information while if it is bad news, the speed of information diffusion would be much slower. It is well documented that the degree of information diffusion is much faster for larger companies (see Chae, 2005). Therefore, we expect that the explanatory power of fundamental factors on small-cap SPM would be more significant than that on large-cap stocks.

In this paper, we address 3 main research questions. Are fundamental and momentum 
analyses complementary rather than competitive in terms of their informativeness for SPM? Does fundamental analysis have more explanatory power for the movements in small cap stock prices than in large cap stock prices? And what is the relative importance of fundamental and momentum variables in predicting future SPM over different investment horizons?

Although most active portfolio managers claim that they are interested in investing for the long term, stock price momentum continues to be one of the most frequently considered variables for developing trading strategies. In practice, momentum is fundamental to many active portfolio managers while the importance of accounting information is often neglected because its short term predictive ability for SPM is less accurate. Therefore, by showing that the use of accounting information as part of a fundamental approach to equity analysis can add value to standalone momentum analysis, the empirical findings of this paper are useful for long-term investors and portfolio managers who are concerned with temporary deviations of stock prices from intrinsic values which can often arise. Our findings also have policy implications for regulators who are interested in the behavioral aspects of momentum traders that can at times, move asset prices excessively within a short time.

This paper, in essence, decomposes the movements in stock prices into a fundamental component driven by accounting information and an investor sentiment component driven by time-series momentum for a sample of large cap and small cap stocks listed on some of the world's largest and most active exchanges in the United States, including the New York Stock Exchange (NYSE) and NASDAQ. The contribution of this paper is as follows. The paper provides additional evidence that accounting variables are useful in explaining stock price movements over longer-term investment horizons. The paper decomposes SPM into factors that are driven by investors employing either momentum or fundamental analyses or all the other factors, which are aggregated into an unobserved common factor. This allows us to 
investigate under what circumstances SPM may be strongly influenced by short-term investors who tend to use momentum analysis based on daily share price fluctuations or longterm investors who tend to use fundamental analysis based on lower frequency accounting information. And the paper unambiguously shows that the greater information asymmetry regarding small-cap stocks influences the predictive power of accounting information over and above momentum analysis, particularly over longer investment horizons.

The rest of the paper is organized as follows. Section 2 provides an overview of the relevant literature. Section 3 describes the data and approach used in our analyses whilst Section 4 discusses the empirical results. Finally, conclusions are provided in Section 5.

\section{Fundamental Analysis vs. Momentum Analysis}

\subsection{Fundamental Analysis}

Fundamental analysts use accounting and other information to study a company’s underlying performance. They investigate financial statements of the firm and its competitors in estimating the future evolution of the value of the company hence, its stock price movements. One of the major purposes of accounting practice is to help readers of financial statements forecast a company's future cash flows (FASB, 1978). If the information on financial statements reflects the fundamental values, then the accounting information for a firm should explain a significant proportion of SPM (See Ou and Penman, 1989). However, the literature so far yields mixed results in finding a link between stock performance and accounting measures.

Although a significant proportion of stock price movement occurs because investors revise their expectations of future cash flows, neither expected cash flows nor discount rates 
are observable and the traditional approach is to predict them and calculate cash flow news and discount rate news as functions of the predictive variables. As Chen, Da and Zhao (2013) note, there is a growing literature that shows (with different sample periods or cash flow measures) cash flow news can be more important than what has traditionally been believed (Ang and Bekaert 2007; Larrain and Yogo 2008; Chen 2009, Binsbergen and Koijen 2010; Chen, Da, and Priestley 2012). They make use of the prevailing market (consensus) earnings forecasts to back out the firm-specific implied cost of equity capital (ICC).

Both Ng et al. (2013) and Chen, Da and Zhao (2013) show that accounting information contained in revisions in analysts' consensus earnings forecasts can explain a large proportion of SPM over longer investment horizons compared to shorter horizons. This is consistent with Chen and Zhang (2007), who provide theory and evidence showing how accounting variables explain cross-sectional stock returns. Based on Zhang's (2000) framework used for linking equity value to accounting measures of underlying operations, they derive SPM as a function of earnings yield, equity capital investment, and changes in profitability, growth opportunities, and discount rates. Empirical results of their paper show that the accounting variables explain about $20 \%$ of the cross-sectional price variation.

The upside of fundamental analysis is that it has an intuitive link to SPM. It should, at least in theory, represent the long term, intrinsic value of a stock. However, the downside is that fundamental analysis is not capable of reflecting the short term movements in stock prices. There could be many reasons for this: quarterly reporting of financial reports or delays in operational processes to reflect new market conditions into earning's figures and so on. The most critical weakness of fundamental analysis is that it does not accurately predict SPM, in the short term. 


\subsection{Momentum Analysis}

Momentum analysts focus mainly on future stock prices given past patterns in stock price movements but they also take into account psychological aspects in the demand for a company’s stock. Stock prices fluctuate tremendously from day to day. Momentum analysts typically believe that past stock prices are good indicators of future SPM. Momentum analysts form their expectation of future SPM based on the past price information or ‘momentum' factors. They employ many techniques, including the use of charts. Using charts, momentum analysts seek to identify price patterns and market trends in financial markets and attempt to exploit these patterns. Thus, traders and portfolio managers continue to use momentum analysis to formulate buy and sell decisions for stocks.

There is much academic interest in the effects of momentum on asset prices. For example, Chen et al. (2014) examine the profitability of using revenue, earnings, and price momentum strategies in an attempt to understand investor reactions when faced with a multitude of information on firm performance in various scenarios. Also Taylor (2014) examine the performance of an important set of momentum-based technical trading rules applied to all members of the Dow Jones Industrial Average (DJIA) stock price index over the lengthy period from 1928 to 2012 and find that profits evolve slowly over time, are confined to particular episodes primarily from the mid-1960s to mid-1980s, and rely on the ability of investors to short-sell stocks. Other recent studies include Zhu and Zhou (2009), Marx (2012), Fama and French (2012), Moskowitz, Ooi and Pederson (2012), Bajgrowicz and Sxaillet (2012), Menkhoff et al. (2012), and Bregantini (2013).

One of the simplest and most widely used trading strategies based on momentum analysis is the Moving Average (MA) rule. It is an objective rule-based trading strategy in which buy and sell signals are determined by the relative magnitudes of short and long term 
MAs. Extant studies based on MA rules include Acar and Satchell (1997), Chiarella, He and Hommes (2006) and Menkhoff (2010). The MA rule often leads investors to invest either with or against the trend (ie., momentum or contrarian trading) since it assumes that prices trend directionally. It takes advantage of price trends, captured as the gap between two MAs computed over different horizons.

The upside of momentum analysis is that there is much evidence indicating that it can accurately predict short term movements in stock prices and the trade can be profitable (see Jegadeesh and Titman, 1993, 2001). This is because there is autocorrelation in stock price processes (see Hong and Satchell, 2013). Moreover, it reflects the behavioral aspects of SPM which is largely ignored in fundamentals-based analyses. This may be another reason why momentum analysis performs better than fundamental analysis in the short term.

However the downside is that it has no theoretical basis and merely explains the stylized facts in the market and investors' behavior. In particular, it is greatly influenced by herding behavior and the crowds do not necessarily predict SPM correctly. Another drawback is that it only uses historical information and has no forward-looking aspect. This typically works against momentum analysis when there are significant regime shifts in market conditions or in the macroeconomic environment. Momentum variables, constructed on the basis of historical information, would not be able to capture the future SPM that deviate significantly from historical price-patterns.

\subsection{Blending the Two}

In short, fundamental analysts seek to determine the intrinsic value of the company while momentum analysts tend to trade based on market forces such as the supply and demand of the stock concerned. We have seen that both approaches have their own merits and limitations. 
Therefore, it would be natural to assume that both fundamental and momentum factors affect stock price movements but surprisingly, there is little evidence to support this conjecture. Existing studies that fail to draw a strong complementary relationship for both sets of determinants tend to focus only on the accounting side of the story. However, stock price momentum could be very noisy. Hence, omitting momentum related variables may obscure the more stable, long term relationship between SPM and accounting information. As such, this paper investigates whether and to what extent accounting and momentum analyses could be complementary to each other for explaining SPM.

Although not applied to the equity market, one of the earliest works, reporting the complementary nature of momentum and fundamental analyses is Taylor and Allen (1992). They argue that about $90 \%$ of foreign exchange market dealers rely on both momentum and fundamental analyses. The four factor model of Cahart (1997) is also a good example of the complementary nature of momentum and fundamental analyses. In that well accepted asset pricing model, Cahart (1997) shows momentum is significant in explaining mutual fund performance alongside Fama and French's (1993) three factor model, which depends on accounting information (market capitalization and the book-to-market ratio) as well as the market risk premium.

Bettman, Sault and Schultz (2009) note that models simultaneously incorporating both fundamental and momentum explanatory variables for equity prices are rarely used. They provide preliminary evidence to support that fundamental and momentum variables could be complementary in explaining SPM, using US data from 1983 to 2002. However, they only include the 5 day lagged price, book value of the firm's equity, diluted earnings per share (EPS) and consensus EPS forecasts to explain SPM. And the analysis relies on simple OLS estimations. This paper extends and improves upon the extant literature by providing a more comprehensive investigation with more appropriate and robust econometric techniques. 


\section{Data and Methodology}

\subsection{Data and Portfolio Construction}

We base our analyses on all stocks in the Russell 3000 index that have monthly and quarterly data available in the Centre for Research in Security Prices (CRSP) U.S. stock databases between January 1999 and December 2012. Since one of the main objectives of this paper is to separately investigate the explanatory power conditional on firm size, the sample coverage in the Russell 3000 index is more appropriate than other frequently used US equity indices such as the S\&P500. Our sample consists of all Russell 3000 index companies for which long term analyst earnings forecasts could be obtained from the Institutional Broker Estimate System (IBES). Hence, we study a total sample of 774 firms with data available from both IBES and CRSP.

We follow Chen and Zhang (2007) and take the first available consensus earnings forecast for a given month to ensure that their growth opportunity measure incorporates the current month's earnings information. This ensures that the forecast obtained for month $t$ covers the long term forecast from month $t$. Whilst Chen and Zhang (2007) trim $0.5 \%$ of the extreme observations at the top and bottom ends of the distribution for all variables used in their study to systematically eliminate outliers, such a trimming procedure is not suitable in our case for several reasons. First, trimming is done based on the distribution for the whole sample, not per period. Second, a $0.5 \%$ criterion yields only the largest and the smallest 0.72 observations subject to trimming making the $0.5 \%$ trimming criteria inappropriate for our analyses. Moreover, our sample period covers the recent 2007-2008 Global Financial Crisis. During financially distressed periods, stock price co-movements increase due to the propagation of distress, which is typically associated with greater declines in market values (Berger and 
Pukthuanthong, 2012). More specifically, financial distress is associated with the balance sheet contraction of individual firms. Such balance sheet contraction affects the accounting variables we employ in this paper and hence this is already effectively accounted for in the model. For these reasons, we use the entire sample for our analyses without trimming any observations.

The Russell 3000 index represents about 98\% of all US equities by market value. Because of its broad diversification and large number of constituents, this index often makes for a popular alternative to a representative total market index such as the Wilshire 5000. The Wilshire 5000 index, which is considered to be the benchmark for U.S. total market returns, includes some stocks that are almost impossible to trade. The more stringent requirements for inclusion into the Russell 3000 index presents a better representation of the universe of actively traded stocks when compared to the alternatives like the Wilshire 5000 (See Russell Investments, 2013).

We follow the approach of Chen and Zhang (2007) in our sample construction but we differentiate our work with the use of stock portfolio-level analyses. Chen and Zhang use a pooled sample but this is not appropriate for our study as we also estimate a state space model. Hence, instead we construct stock portfolios based on firm size. To do this, all per share measures are multiplied by the number of shares outstanding (from IBES) to obtain the aggregated values at the individual firm level. This gives rise to a primary sample extending from 1999 to 2012 with 1,853,124 firm-month observations. We then construct two size portfolios each comprising 387 firms, split around the median value of all sample firms' stock market capitalization. The top portfolio (portfolio 1) represents large cap stocks and the bottom portfolio (portfolio 2) represents small cap stocks.

The firm-level accounting data are downloaded from the Compustat North America database and Thomson Reuters' Worldscope database. Stock prices are sourced from 
Bloomberg and earnings forecasts data are extracted from the Institutional Broker Estimate System (IBES). All accounting data are observed quarterly while stock prices are observed monthly.

As the accounting data are available at the quarterly frequency while stock price data is commonly studied at the monthly frequency, this creates a mixed-frequency problem. In order to overcome this, we need a precise understanding of the evolution of our quarterly data over unobserved periods. There are two different types of data in our sample, stocks and flows. Stock data are snapshots of the measured variable at a given point in time, whereas flow data represent an accumulation over a given period. Monthly observations of flow variables could be cumulated over a quarter and become the end of the quarter observation. In reverse, this means that the end-of-quarter observations for flow variables can be decomposed into daily observations. However this does not apply to stock variables. Since all our quarterly observed variables are flow variables, weighted average is used under this assumption.

Table 1 shows the descriptive statistics of the sample data. The descriptive statistics of our sample data are comparable with those of Chen and Zhang (2007). Despite the difference in the sample period investigated, our summary statistics indicate that the aggregated portfolio level data that we examine is comparable to the firm level data used in Chen and Zhang (2007). We include Table 1 panel A and C of Chen and Zhang (2007) in Appendix 1, to facilitate this comparison and to validate our sample. We next discuss the theoretical link from our portfolio analyses to Chen and Zhang’s (2007) firm-level valuation model.

(Insert Table 1 here) 


\subsection{A Model of Equity Value and Stock Returns: Fundamental Analysis}

Our empirical analyses are theoretically grounded in the equity valuation model of Zhang (2000) and follows Chen and Zhang (2007) in establishing the theoretical relationship between stock returns and accounting fundamentals. This section briefly introduces the equity valuation model that is detailed in Chen and Zhang (2007).

The model measures the characteristics of the underlying operations of a company using the links between future cash flows and the observed accounting data in valuing equity. Equity value is a function of two basic operational attributes: scale and profitability, hence the value of a company amounts to forecasting the relative scale and profitability of future operations with respect to those on current operations. As expected, profitability (ROE) is a key measure in this model and it measures a firm's ability to generate value from the invested capital and indicates how the firm is likely to adjust its operations going forward. The advantage of this model is that it embeds the firm's value-creating capital investment decisions within the set of available opportunities as characterized by options to grow and to downsize or abandon. (See Berger, Ofeck and Swary, 1996 and Berk, Green and Naik, 1999 for the links between real options and firm valuation.)

Let $V_{t}$ be the value of an all equity-finance firm at date $t . B_{t}$ is the corresponding book value of equity. $X_{t}$ is the earnings generated in period $t$, and $g_{t}$ is the firm's growth opportunities as perceived at $t . g_{t}$ is defined as the percentage by which the scale of operations (capital invested) may grow. Let $q_{t} \equiv X_{t} / B_{t-1}$ be profitability (ROE) at time $t$. Let $E_{t}\left(X_{t+1}\right)$ be the expected next-period earnings, $k$ is the earnings capitalization factor, and $P\left(q_{t}\right)$ and $C\left(q_{t}\right)$ are the put option to abandon operations and the call option to expand operations, respectively. $P\left(q_{t}\right)$ and $C\left(q_{t}\right)$ are normalized by the scale of operations, $B_{t}$. To simplify the analysis, profitability is assumed to follow a random walk, $\tilde{q}_{t+1}=q_{t}+\tilde{e}_{t+1}$. Chen and Zhang 
(2007) derive the valuation function of equity as

$$
V_{t}=B_{t}\left[q_{t} / r_{t}+P\left(q_{t}\right)+g_{t} C\left(q_{t}\right)\right] \equiv B_{t} v\left(q_{t}, g_{t}, r_{t}\right)
$$

where $v\left(q_{t}, g_{t}, r_{t}\right) \equiv q_{t} / r_{t}+P\left(q_{t}\right)+g_{t} C\left(q_{t}\right)$. This implies that the equity value can be decomposed into the amount of equity capital invested, $B_{t}$, and the value per unit of capital, $v$, which is a function of profitability $\left(q_{t}\right)$, growth opportunities $\left(g_{t}\right)$, and the discount rate $\left(r_{t}\right)$. Zhang (2000) shows that $v$ is an increasing and convex function of $q_{t}$.

Now consider $\Delta V_{t+1}$, the change in equity value from date $t$ to date $t+1$. Define $v_{1} \equiv$ $\mathrm{d} v / \mathrm{d} q_{t}$ and $v_{3} \equiv \mathrm{d} v / \mathrm{d} r_{t} . \mathrm{d} v / \mathrm{d} g_{t}$ is $E\left(q_{t}\right)$ and need not to be defined again. Let $D_{t}$ be the dividends paid in period $t+1$. Chen and Zhang (2007) derive the period $\mathrm{t}+1$ stock return, denoted $R_{t+1}$ as

$$
R_{t+1}=\left[\frac{X_{t+1}}{V_{t}}\right]+v_{1}\left[\frac{B_{t}}{V_{t}} \Delta q_{t+1}\right]+\left[\left(1-\frac{B_{t}}{V_{t}}\right) \frac{\Delta B_{t+1}}{B_{t}}\right]+C\left(q_{t}\right)\left[\frac{B_{t}}{V_{t}} \Delta g_{t+1}\right]+v_{1}\left[\frac{B_{t}}{V_{t}} \Delta r_{t+1}\right]
$$

Eq. (2) shows that the stock return is a function of the earnings yield, the change in profitability, the change in equity capital, the change in growth opportunities, and the change in the discount rate.

Based on the relationship represented in Eq. (2), Chen and Zhang (2007) run the following approximate regression.

$$
R_{i t}=\alpha+\beta x_{i t}+\gamma \Delta \hat{q}_{i t}+\delta \Delta \hat{b}_{i t}+\omega \Delta \hat{g}_{i t}+\varphi \Delta \hat{r}_{i t}+e_{i t}
$$

where $R_{i t}$ is the annual stock return; $x_{i t}=X_{i t} / V_{i t-1}$ is the earnings yield divided by the 
beginning-of-period market value of equity; $\Delta \hat{q}_{i t}=\left(q_{i t}-q_{i t-1}\right) B_{i t-1} / V_{i t-1}$ is the change in profitability, adjusted by the beginning-of-period ratio of the book value of equity to the market value of equity, with profitability defined as the return on equity (ROE); $\Delta \hat{b}_{i t}=\left[\left(B_{i t}-B_{i t-1}\right) / B_{i t-1}\right]\left(1-B_{i t-1} / V_{i t-1}\right)$ is capital investment, adjusted by one minus the beginning-of-period book-to-market ratio; $\Delta \hat{g}_{i t}=\left(g_{i t}-g_{i t-1}\right) B_{i t-1} / V_{i t-1}$ is the change in growth opportunities, adjusted by the beginning-of-period book-to-market ratio; $\Delta \hat{r}_{i t}=\left(r_{t}-r_{t-1}\right) B_{i t-1} / V_{i t-1}$ is the change in the discount rate, adjusted by firm's beginning-ofperiod book-to-market ratio. We take the five accounting variables in Eq. (3) as our fundamental variables for explaining stock price movements.

\subsection{The Model: Enhancing with Momentum Analysis}

We define the stock price movements as price changes relative to initial price (without dividends) following the definition of Chen, Da and Zhao (2013). This is equivalent to capital gain returns. Therefore, for portfolio $i$, the monthly stock price movements from month $t-1$ to month $t$ could be denoted as

$$
\Delta p_{i, t}=\frac{p_{i, t+h}-p_{i, t}}{p_{i, t}}
$$

where $i=(1,2) . \Delta p_{i, t}$ is the monthly stock return. We classify two groups of variables: fundamental (i.e. accounting-based) variables and momentum (ie. price based) variables. Fundamental variables are those used in Chen and Zhang's (2007) valuation model and include earnings yield $(x)$, equity capital investment $(\Delta b)$, changes in profitability $(\Delta q)$, 
growth opportunities $(\Delta g)$, and discount rates $(\Delta r)$. Past returns are often used to explain current returns (Jegadeesh and Titman,1993 and Chen, Hong and Stein, 2001) and past stock returns are also used to explain momentum in stock returns (Moskowitz, Ooi and Pederson, 2012). Therefore, momentum variables include various return moving averages (MAs) over different measurement horizons. We include five lagged returns, lagged by 1, 3, 6, 9 and 12 months, and name them as $T_{1 M, i, t}, T_{3 M, i, t}, T_{6 M, i, t}, T_{9 M, i, t}$ and $T_{12 M, i, t}$, respectively.

The five lagged returns are selected to capture the short term, medium term and long term influence of momentum variables.

We first examine the impact of having both fundamental and momentum variables under the traditional OLS framework. Hence we run

$$
\Delta p_{i, t}=\alpha+\beta_{i} F_{i, t}+\gamma_{i} T_{i}+\varepsilon_{i, t}
$$

where $\beta_{i}=\left(\begin{array}{lllll}\beta_{i, 1} & \beta_{i, 2} & \beta_{i, 3} & \beta_{i, 4} & \beta_{i, 5}\end{array}\right), \quad \gamma=\left(\begin{array}{lllll}\gamma_{i, 1} & \gamma_{i, 2} & \gamma_{i, 3} & \gamma_{i, 4} & \gamma_{i, 5}\end{array}\right)$ , $F_{i, t}=\left(\begin{array}{lllll}x_{i, t} & \Delta q_{i, t} & \Delta b_{i, t} & \Delta g_{i, t} & \Delta r_{i, t}\end{array}\right), T_{i, t}=\left(\begin{array}{lllll}T_{1 M, i, t} & T_{3 M, i, t} & T_{6 M, i, t} & T_{9 M, i, t} & T_{12 M, i, t}\end{array}\right)$

We first provide a directly comparable result to the existing literature explaining crosssectional returns using our size portfolios by estimating Eq. (5) using OLS. Our preliminary check on the data reveals that the sample suffers from heteroskedasticity. This is resolved by using the Newey-West correction for standard errors, that is akin to using the generalized least squares (GLS) method.

While it is expected that the fundamental and momentum variables will jointly explain a large proportion of SPM, there remains the possibility of omitted variable bias in Eq. (5). It is highly likely that there exists other factors causing stock prices to change and these factors 
are stochastic in nature. Hence, we aggregate these factors into one variable and estimate it using a Kalman filtering technique and name it $Z$. Having a conditioning variable, $Z$, in the regression has two advantages: (i) it ensures that our residual term is i.i.d. by reducing potential multicollinearity and omitted variable bias and (ii) it allows us to precisely quantify the level of incremental contribution to the predictive power of the model, which will be investigated in the next section. This will be further discussed in detail in Section 3.5.

Therefore we have

$$
\Delta p_{i, t}=\alpha+\beta_{i} F_{i, t}+\gamma_{i} T_{i}+\lambda Z_{t}+\varepsilon_{i, t}
$$

where all parameters and variables are as previously defined.

Running Eq. (6) yields the relationship between variations in stock prices and the fundamental and momentum variables.

\subsection{Estimation Method: State Space Model}

Note that the variable $Z$ does not have subscript $i$ as $Z$ will be estimated from both size portfolios simultaneously. Hence all portfolios share the same $Z$. This is equivalent to frailty in statistics (see Duffiee et al., 2009). As previously stated, a conditioning variable, Z, represents all the market wide common stochastic factors that cause stock prices to change. Although used under a completely different framework, Goh et al. (2012) notes the importance of this type of variable and uses an equivalent approach and also refer to it as variable Z. In explaining bond risk premia using momentum variables, Goh et al. (2012) includes an economic variable, $Z$, which includes macroeconomics factors from Ludvigson and Ng (2009). Instead, we apply a standard Kalman filtering technique to extract the same 
information from the market data.

Using a state space model ensures that we suffer less from omitted variable bias since it is not possible to include all variables that potentially affect stock price movements. Adopting a filtering approach in the estimation of a state space model also allows us to be less prone to an over-fitting problem. In implementing the state space model, we follow Hamilton (1994) closely. In this section, however, we describe and justify the structure of the state equation. Filtering also has major advantages over principal component analysis (PCA). First, filtering yields a more parsimonious regression model whilst allowing us to include more information. We must decide the number of components to include in a PCA and the criterion for this becomes ambiguous when the explanatory power of the first component is not sufficiently large. Many choose the number of PCs that can explain more than an arbitrary level of all movements in the underlying variables of interest (e.g. 90\%) but this may require multiple PCs to be included in subsequent regression analyses. ${ }^{3}$ Second, filtering allows us to project the common variable, $Z$, by giving it a structure. When using PCA, we cannot forecast the value of principal components. Therefore filtering is more appropriate for explaining future stock returns.

Under the assumption of linearity and multivariate Gaussian error terms, parameters of state equations estimated using Kalman filter are optimal. Eq. (7) is the observation equation, where we intend to estimate $Z$ with the state equation. The state equation is modelled with an AR(1) process.

$$
Z_{t}=\rho Z_{t-1}+\sqrt{1-\rho^{2}} \omega_{t}
$$

\footnotetext{
3 For example, Pukthuanthong and Roll (2009) use the first 10 principal components from a PCA to explain country-level stock index returns at the daily frequency.
} 
where $-1<\rho<1 . Z$ is a factor that includes commonalities of the sample portfolios. Therefore $Z$ represents macroeconomic and financial market conditions that commonly affect the US equity market. The constituents of the Russell 3000 index represents approximately $98 \%$ of the investable equities in the US stock market. By including $Z$, we are controlling for unobserved macroeconomic, market wide variability that is known to exist. It is well known that macroeconomic factors are cyclical, therefore, $Z$ is modelled by an $\operatorname{AR}(1)$ process, with quarterly periods, consistent with the data interval of the fundamental variables. The parameter $\rho$ would represent the cyclicality of the variable $Z$.

If we employ a simple $\operatorname{AR}(1)$ process of $Z_{t}=\rho Z_{t-1}+\omega_{t}$, the state equation will introduce an identification problem. Parameters, $\beta, \gamma, \lambda$ and $\rho$, are estimated by iteratively maximizing the likelihood function where the state variable $Z$ is unobserved. The same values of the likelihood function could be obtained with various combinations of the $\lambda$ and $Z$, as long as the multiples of the two are the same. Controlling for the conditional variance of $Z$ can correct this identification problem. Therefore we impose a constraint that the conditional variance of $Z$ is equal to 1 . This is equivalent to performing a GLS estimation of the state equation. The proof is in Appendix 2. Once we filter the state variable $Z$ and forecast one period ahead for $Z$ using the state equation.

If $Z$ properly represents the market wide common shock, our ex-ante expectation of $\lambda$ is positive and significantly different from zero. The sign and the statistical significance of the estimated parameter of the variable $\rho$ cannot be predicted because the cyclicality in market wide shocks could have already been absorbed in the momentum variables. The sign and the statistical significance of the estimated coefficient would depend on the explanatory power of the autoregressive (AR) terms and the market condition. If the AR terms over-react to macrolevel cyclical shocks, the estimated coefficient of $\rho$ could be negative and if the AR terms under-react to such shocks, the estimated coefficient could be positive. If the AR terms could 
fully explain the variability from the macro-level cyclical shocks, then the coefficient may be statistically insignificant.

For convenience, we will refer to these models as follow, hereafter.

OLSF Model: $\Delta p_{i, t}=\alpha+\beta_{i} F_{i, t}+\varepsilon_{i, t}$

OLSM Model: $\Delta p_{i, t}=\alpha+\gamma_{i} T_{i, t}+\varepsilon_{i, t}$

OLSMF Model: $\Delta p_{i, t}=\alpha+\beta_{i} F_{i, t}+\gamma_{i} T_{i, t}+\varepsilon_{i, t}$

State Space Model: $\Delta p_{i, t}=\alpha+\beta_{i} F_{i, t}+\gamma_{i} T_{i, t}+\lambda Z_{t}+\varepsilon_{i, t}$

\section{Empirical Results}

\subsection{Fundamental Analysis with Momentum Analysis under OLS Specification}

The extant literature investigating the impact of accounting information and/or momentum variables typically use OLS (See inter alia, Chen and Zhang, 2007, Bettman, Sault and Schultz 2009, Binsbergen and Koijen, R. 2010, Bajgrowicz and Sxaillet, 2012). In this section, we combine the fundamental variables suggested by Chen and Zhang (2007) and various momentum indicators following the traditional OLS approach and compare the results to the cases when separate regressions are employed, i.e we are comparing the result of OLSF in Eq. (8) $\left(\Delta p_{i, t}=\alpha+\beta_{i} F_{i, t}+\varepsilon_{i, t}\right)$ and OLSM in Eq. (9) $\left(\Delta p_{i, t}=\alpha+\gamma_{i} T_{i}+\varepsilon_{i, t}\right)$ to OLSFM in Eq. (10) $\left(\Delta p_{i, t}=\alpha+\beta_{i} F_{i, t}+\gamma_{i} T_{i}+\varepsilon_{i, t}\right)$. Table 2 reports the results of OLSF and OLSM and Table 3 reports the results of OLSFT.

(Insert Table 2 here)

(Insert Table 3 here) 
In comparing OLS results presented in Tables 2 and 3 we note several striking results. When momentum indicators are used in stand-alone regressions in Table 2, they are much less effective than when they are used alongside accounting information in Table 3. For instance, for large cap stocks in Panel $A$, the longer term momentum variables, $T_{6 \mathrm{M}}$ and $\mathrm{T}_{12 \mathrm{M}}$ are only mildly significant at the $10 \%$ level whilst for small cap stocks in Panel $\mathrm{B}, \mathrm{T}_{3 \mathrm{M}}$ is the only statistically significant momentum variable. This indicates that there is limited power in using momentum analysis alone and that it is beneficial to use a combination of fundamental and momentum variables when explaining stock price movements.

As expected, the $\mathrm{R}^{2}$ of the small cap portfolio is larger than that of the large cap portfolio. This result is consistently supported in all subsequent empirical models where we include both the fundamental and momentum variables suggesting that accounting and timeseries momentum information can collectively account for a larger proportion of SPM in smaller stocks with a less transparent information environment.

It can be seen in Table 3 that when fundamental and momentum variables are used jointly to explain stock return variations, the adjusted $\mathrm{R}^{2}$ significantly increases indicating that momentum variables do provide substantial incremental information for explaining SPM over fundamental variables. This evidence suggests that there is a complementary role for the two types of security analyses. From Table 2 and 3, we can see that the statistical significance of some of the coefficients improve, when they are used jointly in an OLS estimation compared to when they are estimated separately. For instance, the estimates for the momentum indicators $T_{1 M}, T_{3 M}, T_{6 M}, T_{9 M}$ and $T_{12 M}$ all improve for the large-cap portfolio whilst the estimates for both fundamental and momentum variables, $\Delta b, \Delta g, T_{1 M}, T_{6 M}, T_{9 M}$ and $T_{12 M}$ improve for the small-cap portfolio. 
Our OLS results affirm the extant literature. The explanatory power of our OLS models (measured by $\mathrm{R}^{2}$ and the adjusted $\mathrm{R}^{2}$ values) are comparable to those of Bettman et al. (2009) as they also try to explain SPM with accounting variables. They report a $\mathrm{R}^{2}$ of 0.429 when only accounting fundamentals are regressed (Table 4 of Bettman et al, 2009) and an adjusted $\mathrm{R}^{2}$ of 0.7686 when fundamental and momentum variables are combined (Table 5 of Bettman et al, 2009). All variables are significant in the expected direction.

While our results are fairly consistent with the extant literature, we show with the use of several momentum variables representing price-based information aggregated over different time horizons, that the coefficient of the one month lagged return, $T_{1 M}$, is positive for both size portfolios when only momentum variables are used to explain SPM. However, they become negative and also statistically significant when the model is augmented with fundamental variables. This suggests that some of the short term momentum could be captured by accounting information and the two types of variables have some overlap in their stock price informativeness.

Taken together, the evidence suggests that the two sets of variables are complementary in nature rather than substitutes for one another. However, it should be noted that whilst the OLS results do not suffer from serial correlation or heteroskedasticity as they are controlled with the Newey-West method, the residuals from Eq. (10) do reject the Ramsey Regression Equation Specification Error Test (RESET). This suggests that the standard OLS model may be suffering from omitted variable bias and we specifically control for that with a state space modelling approach in the next sub-section. ${ }^{4}$

\footnotetext{
${ }^{4}$ The Ramsey RESET provides a general specification test on the linear regression model for whether nonlinear combinations of the fitted values help to explain the response variable. The test is one of the most popular proxy tests for omitted variable bias.
} 


\subsection{State Space Modelling}

To overcome omitted variable bias, we next use a state space model specified by Eqns. (6)(7). The results are provided in Table 4.

(Insert Table 4 here)

In Table 4, we observe that the coefficient of the common latent variable is statistically significant and positive in explaining the returns of both size portfolios. Furthermore, the latent variable provides incremental explanatory power for variations in monthly SPM as the adjusted $\mathrm{R}^{2}$ is higher when it is included alongside the fundamental and momentum variables. Taken together this evidence indicates that the latent variable is indeed important for picking up those unobservable common factors that influence SPM and that the OLS models that have been used in the extant literature suffer from omitted variable bias. Hence, prior studies have not provided an accurate picture of the relative importance of fundamental and momentum analyses for security pricing.

The state space model is well specified and more appropriate for modelling stock price movements as it yields non-serially correlated homoscedastic residuals with the latent variable $Z_{t}$, designed to absolve most of non-i.i.d. aspects of stock returns. Nonetheless, the state space model does not alter the signs of the estimated coefficients that are statistically significant in the combined OLSFT model. Duffie et al. (2009) also finds a statistically significant unobserved market wide factor in modelling the risk of large default losses. Our finding may be considered its equivalent in equity market returns. 


\subsection{Firm Size Analysis}

The unobserved common factor has a significant and positive impact on the returns of both the large-cap and the small-cap companies but has a notably larger impact on the stock returns of the latter. This indicates that small cap stocks are more prone to market wide shocks.

In general, we find that larger firms tend to be more sensitive to accounting-based information. First, the performance of large-cap stocks is more dependent on earnings. Earnings exerts a greater economic impact on the stock returns of large firms relative to smaller firms as one standard deviation increase in earnings yield (x) would increase larger firms’ monthly stock returns by $1.176 \%$ but only by $0.345 \%$ for smaller firms.

Second, changes in investment $(\Delta \mathrm{b})$ have significant effects on large cap firms' stock performance but not on the small cap firms. A one standard deviation increase in investment made can increase monthly stock returns by $0.269 \%$ in large firms but only $0.14 \%$ in small firms. This corroborates with evidence that the more significant investments made by largecap companies tends to have greater impact on their performance.

Third, revisions in analyst's long term earnings forecasts $(\Delta \mathrm{g})$ have a much higher impact on large cap stock returns as a one standard deviation increase in the long term growth forecasts can increase stock returns by $0.713 \%$ and $0.187 \%$ for large and small firms, respectively. This is because analysts tend to make much more accurate forecasts on the future performance of the large cap companies as information is more readily available to analysts. Also, trading of large cap stocks tends to be driven more by stock analysts' recommendations so it is expected that analyst earnings forecasts would provide more explanatory power for stock performance. 
In contrast, changes in monthly profitability $(\Delta q)$ are not significantly related to large cap stock performance but are important for explaining small cap stock returns. This is consistent with the notion that the stock returns of larger companies are less sensitive to the short term swings in company profits.

We note that larger firms are also more sensitive to momentum variables as all momentum variables are significant for the large cap stocks, while the six month lag return $\left(\mathrm{T}_{6 \mathrm{M}}\right)$ is not significant for explaining variations in small cap stock returns. This suggests that in the medium term, price-based information is not as important for smaller stocks relative to fundamental information.

Fourth, changes in the discount rate $(\Delta \mathrm{r})$ have a statistically significant negative influence on both portfolios' returns. It has much higher impact on small cap stock returns as a one standard deviation increase in the discount rate can decrease stock returns by $1.039 \%$ and $1.658 \%$ for large and small firms, respectively. The negative relationship is as expected and is consistent with Chen and Zhang (2007). The larger impact on small firms is also intuitive as smaller companies are more prone to changes in discount rates. For example, small companies more likely to experience liquidity squeeze when the discount rate increases.

The intercept captures the mean return on a given stock portfolio. We note that the intercept is negative and significantly different from zero for large cap stocks while it is not statistically significant for the small cap stocks. This result is consistent with Fama and French (1993) where they find that small cap and value portfolios have higher expected returns — and arguably higher expected risk — than those of large cap and growth portfolios, all other things being held equal. 


\subsection{Robustness Checks}

OLSFT model is a benchmark model that we use to assess the new evidence that can be gleaned from an alternative state space modelling approach. We find that the signs and the statistical significance of the estimated parameters are consistent with the OLSFT model. Compared with the benchmark model, the state space model offers higher explanatory power. Furthermore, the residual of the state space model is less likely to suffer from the omitted variable bias problem.

Next, we test the state space model over various subsample periods. The results for this subsection are not tabulated for brevity but are available upon request. The adjusted $\mathrm{R}^{2}$ of the model remains steady as subsample period changes, ranging from 0.797, in 2000-2012, to 0.886, in $2004-2012$.

Finally, we follow Chen and Zhang (2007) in verifying the robustness of the results obtained from the state space model and analyze various partitions of the sample. We partition the sample companies into quartiles based upon market capitalization. We run separate regressions for the four size portfolios. The results show that for all size quartiles, the regression coefficients have the same signs as predicted by the theoretical model, suggesting that the qualitative results presented are robust across different groupings for firm size.

(Insert Table 5 here) 


\section{Concluding Remarks}

In this paper we revisit the relative importance of fundamental and momentum analyses for stocks. We study a sample of the constituents of the Russell 3000 index from the US over the period from 1999-2012. Using a portfolio level analysis, we consider the differences in the explanatory power of the two main types of predictors for monthly stock price movements. In order to avoid potential omitted variable bias and to improve the explanatory power of our empirical model, we employ a state space model. Our model includes a state variable, which represents an unobservable market wide common factor.

We find that combining fundamental analysis with momentum analysis can substantially enhance the explanatory power for stock price movements, compared to the cases where momentum or fundamental analysis is employed independently. The adjusted $\mathrm{R}^{2}$ increases significantly when both types of variables are included in the estimation model.

We also find that the unobserved common factor is important for explaining SPM. The adjusted $\mathrm{R}^{2}$ increases when the common factor is taken into account indicating improved explanatory power for SPM. Lastly, we find that there exists a significant size effect in the influence of the momentum and fundamental variables on stock price variations reflecting the greater information opacities in smaller firms.

Large cap stock returns are more sensitive to earnings, changes in investments and changes in long term growth expectations than small stocks returns. In contrast, returns of small cap stocks are more sensitive to changes in profitability and changes in discount rates. Both large cap and small cap stock returns are significantly explained by their own past values. The intercept, which captures the mean return on a given stock portfolio, is negative and significantly different from zero for large cap stocks while it is not statistically significant for the small cap stocks. This may indicate that small cap and value portfolios have higher 
expected returns — and arguably higher expected risk — than those of large cap and growth portfolios and is consistent with Fama and French (1993).

The contribution of our paper to the extant literature can be summarized as follows. We empirically find that blending momentum and fundamental analysis is beneficial in explaining stock price movements. However there exists a systematic portion in residual stock price movements that cannot be explained by the two and this factor must be extracted and segregated in order to have a better specified model. Once all these are taken into account, we find that there is a significant size effect. The fundamental variables, momentum variables and unobserved common factor all have different impacts on stock price movements depending on the size of the companies.

Future research on this topic should focus on examining whether there may be differing roles played by fundamental and momentum variables in explaining SPM of growth vs. value stocks. It is likely that the complementary roles of the two approaches can be enhanced for growth stocks where market sentiment regarding future growth prospects can potentially fill more of the gaps in information not satisfactorily provided by accounting-based variables. We leave this investigation for future research endeavours. 


\section{Reference}

Acar, E., Satchell, S., 1997. A theoretical analysis of trading rules: an application to the moving average case with Markovian returns, Applied Mathematical Finance 4, 165 - 180.

Alexeeva, V., Tapon F., 2011. Testing weak form efficiency on the Toronto Stock Exchange, Journal of Empirical Finance 18(4), 661-691.

Amini S, Gebka B, Hudson R, Keasey K., 2013. A review of the international literature on the short term predictability of stock prices conditional on large prior price changes: Microstructure, behavioral and risk related explanations, International Review of Financial Analysis 26, 1-17.

Ang, A., Bekaert, G., 2007. Stock return predictability: Is it there?, Review of Financial Studies 20, 651-707.

Bajgrowicz, P., Sxaillet, O., 2012. Size, value, and momentum in international stock returns, Journal of Financial Economics 106, 473-491.

Berk, J., Green, R., Naik, V., 1999. Optimal investment, growth options, and security returns, Journal of Finance 54, 1533-1607.

Berger, P., Ofeck, E., Swary, I., 1996. Investor valuation of the abandonment option, Journal of Financial Economics 42, 1-31.

Berger, D., Pukthuanthong, K., 2012. Market Fragility and International Crises, Journal of Financial Economics 105(3), 565-580

Bettman, J., Sault, S., Schultz, E., 2009. Fundamental and technical analysis: substitutes or complements?, Accounting and Finance 49, 21-36.

Binsbergen, J. V., Koijen, R., 2010. Predictive regressions: A present-value approach, Journal of Finance 65, 1439-71.

Bollinger, J., 2005. Combining Technical and Fundamental Analysis, CFA Institute Conference Proceedings Quarterly 2005, 60-70.

Bregantini, D., 2013. Moment-based estimation of stochastic volatility, Journal of Banking and Finance 37(12), 4755-4764.

Brock, W., Lakonishok, J., Lebaron, B., 1992. Simple Technical Trading Rules and the Stochastic Properties of Stock Returns, Journal of Finance 47(5), 1731-1764

Chae, J., 2005. Trading Volume, Information Asymmetry, and Timing Information, Journal of Finance 60(1), 413-442.

Carhart, M. M., 1997. On Persistence in Mutual Fund Performance. Journal of Finance 52, 57-82. 
Chen, H. Y., Chen, S. S., Hsin, C. W., Lee, C. F., 2014. Does revenue momentum drive or ride earnings or price momentum? Journal of Banking and Finance 38, 166-185.

Chen, J., Hong, H., Stein, J. C., 2001. Forecasting crashes: Trading volume, past returns, and conditional skewness in stock prices, Journal of Financial Economics 61(3), 345-381.

Chen, L., 2009. On the reversal of return and dividend growth predictability: A tale of two periods, Journal of Financial Economics 92, 128-51.

Chen, L., Da, Z., Priestley, R., 2012. Dividend smoothing and predictability, Management Science 58, 1834-53.

Chen, L., Da, Z., Zhao. X., 2013. What Drives Stock Price Movements?, Review of Financial Studies 26, 841-876.

Chen, P., Zhang, G., 2007. How do accounting variables explain stock price movements? Theory and evidence, Journal of Accounting and Economics 43(2), 219-244.

Chen, L., Zhao, X., 2009. Return decomposition, Review of Financial Studies 22, 5213-49.

Chiarella, C., He, X. Z., Hommes, C., 2006. A dynamic analysis of moving average rules, Journal of Economic Dynamics and Control 30(9-10), 1729-1753.

Duffie, D., Eckner, A., Horel, G., Saita, L., 2009. Frailty Correlated Default, Journal of Finance 64(5), 2089-2123.

Fama, E. F., French, K. R., 1993. Common risk factors in the returns on stocks and bonds., Journal of Financial Economics 33(1), 1-56

Fama, E.F., French, K.R., 2012. Technical trading revisited: False discoveries, persistence tests, and transaction costs, Journal of Financial Economics 105, 457-472.

Financial Accounting Standards Board (FASB), 1978. Statement of Financial Accounting Concepts No.1: Objectives of Financial Reporting by Business Enterprises, FASB, Stamford, CT.

Goh, J., Jiang, F., Tu, J., Zhou, G., 2012. Forecasting Government Bond Risk Premia Using Technical Indicators, Working paper, Singapore Management University.

Grossman, S., Stiglitz, J., 1980. On the Impossibility of Informationally Efficient Markets, American Economic Review 70, 393-408.

Hamilton, J., 1994. Time Series Analysis, Princeton University Press.

Hong, K., Satchell, S., 2012. Defining single asset price momentum in terms of a stochastic process, Theoretical Economics Letters 2(3), 274-277.

Hong, K., Satchell, S., 2013. Time Series Momentum Trading Strategy and Autocorrelation Amplification, Cambridge Working Papers in Economics, 1322. 
Jegadeesh, N., Titman, S., 1993. Returns to buying winners and selling losers, Journal of Finance 48, 65-91.

Jegadeesh, N., Titman, S., 2001. Profitability of momentum strategies: an evaluation of alternative explanations, Journal of Finance 56, 699-720.

Larrain, B., Yogo, M., 2008. Does firm value move too much to be justified by subsequent changes in cash flow?, Journal of Financial Economics 87, 200-26.

Levy, R., 1967. Relative Strength as a Criterion for Investment Selection, Journal of Finance 22, 595-610.

Ludvigson, S.C., Ng., S., 2009. Macro Factors in Bond Risk Premia, Review of Financial Studies 22, 5027-67.

Lui, Y.H., Mole, D., 1998. The use of fundamental and technical analyses by foreign exchange dealers: Hong Kong evidence, Journal of International Money and Finance 17(3), 535-545.

Marx, R., 2012. Is momentum really momentum?, Journal of Financial Economics 103, 429453.

Menkhoff, L., 2010. The use of technical analysis by fund managers: International evidence, Journal of Banking and Finance 34, 2573-2586.

Menkhoff, L., Sarno, L., Schmeling, M., Schrimpf, A., 2012. Currency momentum strategies, Journal of Financial Economics 106, 660-684.

Moskowitz T., Ooi, Y. H., Pedersen L.H., 2012. Time Series Momentum, Journal of Financial Economics 104, 228-250.

Ng, L., Solnik, B., Wu, E., Zhang, B., 2013. Characterizing Global Financial and Economic Integration Using Cash Flow Expectations, Working paper, University of WisconsinMilwaukee.

Ou, J., Penman, S., 1989. Financial statement analysis and the prediction of stock returns, Journal of Accounting and Economics 11, 295-329.

Pukthuanthong, K., Roll, R., 2009. Global market integration: A better way to measure it and its application, Journal of Financial Economics, 94 (2), 214-232.

Russell Investments, 2013. Russell U.S. Equity Indexes Construction and Methodology.

Taylor, M., Allen, H., 1992. The use of technical analysis in the foreign exchange market, Journal of International Money and Finance 11, 304-314.

Taylor, N., 2014. The rise and fall of technical trading rule success, Journal of Banking and Finance 40, 286-302. 
Zhang, G., 2000. Accounting information, capital investment decisions, and equity valuation: theory and empirical implications, Journal of Accounting Research 38(2), 271-295.

Zhu, Y., Zhou G., 2009. Technical analysis: An asset allocation perspective on the use of moving averages, Journal of Financial Economics 92(3), 519-544. 


\section{Tables and Figures.}

\section{Table 1.}

Descriptive statistics of the sample

This table reports the descriptive statistics of the following variables. The portfolio return $\left(\mathrm{R}_{t}\right)$ is the monthly return of all sample stocks; earnings yield $\left(\mathrm{x}_{\mathrm{t}}\right)$ is earnings $\left(\mathrm{X}_{\mathrm{t}}\right)$ divided by the beginning-of-period market value of equity $\left(\mathrm{V}_{\mathrm{t}-1}\right)$; profitability change $\left(\Delta \mathrm{q}_{\mathrm{it}}\right)$ is month $\mathrm{t}$ profitability $\mathrm{q}_{\mathrm{t}}$ minus month $\mathrm{t}-1$ profitability $\mathrm{q}_{\mathrm{t}-1}$, where $\mathrm{q}_{\mathrm{t}}=$ $\mathrm{X}_{\mathrm{t}} / \mathrm{B}_{\mathrm{t}-1}$ multiplied by $\mathrm{B}_{\mathrm{it}-1} / \mathrm{V}_{\mathrm{it}-1}$; capital investment $\left(\Delta \mathrm{b}_{\mathrm{it}-1}\right)$ is the change in the book value of equity relative to the prior month scaled by beginning-of-period book value multiplied by $\mathrm{B}_{\mathrm{it}-1} / \mathrm{V}_{\mathrm{it}-1}$; growth opportunity change $\left(\Delta \mathrm{g}_{\mathrm{it}}\right)$ is the change in the median analyst forecast of the long-term growth rate following the current year earnings announcement relative to that of the prior year; the adjusted growth opportunity change is growth opportunity change multiplied by $B_{i t-1} / V_{i t-1}$; discount rate change $\left(\Delta r_{i t}\right)$ is the change of the 10-year US Treasury bond yield over the return period multiplied by $\mathrm{B}_{\mathrm{it}-1} / \mathrm{V}_{\mathrm{it}-1}$. The sample consists of 130,032 firm-month observations over the period 1999-2012.

Panel A1: Monthly descriptive statistics of the total sample

\begin{tabular}{lrrrrrrr}
\hline Total Sample & Mean & Median & Std dev & Min & 1st quartile & 3rd quartile & Max \\
\hline Portfolio Return & $0.36 \%$ & $0.82 \%$ & $4.59 \%$ & $-16.85 \%$ & $-1.98 \%$ & $3.20 \%$ & $10.23 \%$ \\
Earnings yield $(\mathrm{x})$ & 0.06 & 0.07 & 0.03 & -0.12 & 0.05 & 0.07 & 0.10 \\
Profitability change $(\Delta \mathrm{q})(\%)$ & $0.00 \%$ & $0.02 \%$ & $2.27 \%$ & $-13.12 \%$ & $-0.66 \%$ & $0.66 \%$ & $10.76 \%$ \\
Capital investment $(\Delta \mathrm{b})(\%)$ & $0.51 \%$ & $0.52 \%$ & $0.60 \%$ & $-2.18 \%$ & $0.25 \%$ & $0.85 \%$ & $1.80 \%$ \\
Growth opportunity change $(\Delta \mathrm{g})(\%)$ & $0.23 \%$ & $0.23 \%$ & $0.62 \%$ & $-2.52 \%$ & $-0.04 \%$ & $0.51 \%$ & $2.13 \%$ \\
Discount rate change $(\Delta \mathrm{r})(\%)$ & $0.11 \%$ & $0.00 \%$ & $1.33 \%$ & $-8.67 \%$ & $-0.32 \%$ & $0.48 \%$ & $6.06 \%$ \\
B/M ratio & 0.34 & 0.33 & 0.10 & 0.17 & 0.28 & 0.43 & 0.61 \\
\hline
\end{tabular}

Panel A2: Correlation matrix of the total sample

\begin{tabular}{lccrrr}
\hline Correlation Matrix & $\mathrm{R}$ & $\mathrm{x}$ & $\mathrm{dq}$ & $\mathrm{db}$ & $\mathrm{dg}$ \\
\hline Earnings yield $(\mathrm{x})$ & 0.28 & & & & \\
Profitability change $(\Delta \mathrm{q})(\%)$ & 0.11 & 0.22 & & & \\
Capital investment $(\Delta \mathrm{b})(\%)$ & 0.23 & 0.24 & 0.34 & & \\
Growth opportunity change $(\Delta \mathrm{g})(\%)$ & 0.11 & 0.09 & -0.06 & -0.12 & \\
Discount rate change $(\Delta \mathrm{r})(\%)$ & -0.16 & -0.37 & 0.21 & -0.14 & -0.03 \\
\hline
\end{tabular}




\section{Table 2.}

Estimated results of $\Delta p_{i, t}=\alpha+\beta_{i} F_{i, t}+\varepsilon_{i, t}$ and $\Delta p_{i, t}=\alpha+\gamma_{i} T_{i, t}+\varepsilon_{i, t}$.

This table reports the estimation results for Eq.s (8) and (9) in explaining monthly stock price movements of all sample stocks in the Russell 3000 index. Panel A shows the results for the large-size portfolio, portfolio 1, whilst Panel B reports results for the small-size portfolio, portfolio 2. OLS Fundamentals reports OLSF model in Eq.S (8) and OLS Momentum reports OLSM model in Eq.s (9). $\mathrm{R}^{2}$ and Adj $\mathrm{R}^{2}$ rows report the $\mathrm{R}^{2}$ and the adjusted $\mathrm{R}^{2}$ of the regression models. Variable $x$ is earnings divided by the beginning-of-period market value of equity; variable $\Delta q$ is profitability change; capital investment, variable $\Delta b$, is the change in the book value of equity relative to the prior month; growth opportunity change, variable $\Delta g$, is the change in the median analyst forecast of the long-term growth rate; variable $\Delta d$ is the discount rate (10-year US Treasury bond yield) change over the return period. $T_{1 M, i, t}, T_{3 M, i, t}, T_{6 M, i, t}, T_{9 M, i, t}$ and $T_{12 M, i, t}$ are the lagged returns of the portfolio $i$, lagged by 1, 3, 6, 9 and 12 months, respectively. The sample consists of 130,032 firm-month observations over the period 19992012.

$*, * *, * * *$ denote significance at the 10,5 and $1 \%$ level of significance, respectively.

\begin{tabular}{|c|c|c|c|c|c|c|c|}
\hline \multicolumn{8}{|l|}{ Panel A } \\
\hline \multicolumn{4}{|c|}{ OLS Fundamentals } & \multicolumn{4}{|c|}{ OLS Momentum } \\
\hline Variable & Estimated Coeff & t-stat & p-value & Variable & Estimated Coeff & t-stat & p-value \\
\hline$X$ & $0.263 * * *$ & 4.89 & 0.000 & $T_{1 M}$ & $0.346^{* * *}$ & 4.74 & 0.000 \\
\hline$\Delta q$ & 0.016 & 0.13 & 0.900 & $T_{3 M}$ & 0.097 & 1.41 & 0.162 \\
\hline$\Delta b$ & $0.760 * * *$ & 4.57 & 0.000 & $T_{6 M}$ & $-0.117^{*}$ & -1.83 & 0.069 \\
\hline$\Delta g$ & $1.710^{* * *}$ & 2.87 & 0.005 & $T_{9 M}$ & -0.055 & -0.93 & 0.356 \\
\hline$\Delta r$ & $-0.825 * * *$ & -3.67 & 0.000 & $T_{12 M}$ & $-0.097 *$ & -1.66 & 0.098 \\
\hline constant & $-0.019 * * *$ & -5.2 & 0.000 & constant & 0.002 & 1.33 & 0.186 \\
\hline $\mathrm{R}^{2}$ & 0.420 & & & $\mathrm{R}^{2}$ & 0.212 & & \\
\hline Adj $R^{2}$ & 0.402 & & & Adj $R^{2}$ & 0.186 & & \\
\hline \multicolumn{8}{|l|}{ Panel B } \\
\hline \multicolumn{4}{|c|}{ OLS Fundamentals } & \multicolumn{4}{|c|}{ OLS Momentum } \\
\hline Variable & Estimated Coeff & t-stat & p-value & Variable & Estimated Coeff & t-stat & p-value \\
\hline$x$ & $0.093 * * *$ & 3.06 & 0.003 & $T_{1 M}$ & 0.110 & 1.43 & 0.156 \\
\hline$\Delta q$ & $0.214^{* *}$ & 2.01 & 0.047 & $T_{3 M}$ & $0.128 *$ & 1.77 & 0.079 \\
\hline$\Delta b$ & 0.321 & 0.98 & 0.328 & $T_{6 M}$ & -0.001 & -0.01 & 0.994 \\
\hline$\Delta g$ & $0.304^{*}$ & 1.96 & 0.051 & $T_{9 M}$ & -0.042 & -0.64 & 0.521 \\
\hline$\Delta r$ & $-1.244 * * *$ & -5.96 & 0.000 & $T_{12 M}$ & -0.023 & -0.36 & 0.716 \\
\hline constant & 0.002 & 1.04 & 0.302 & constant & 0.002 & 0.86 & 0.392 \\
\hline $\mathrm{R}^{2}$ & 0.454 & & & $\mathrm{R}^{2}$ & 0.046 & & \\
\hline Adj $R^{2}$ & 0.437 & & & Adj $R^{2}$ & 0.014 & & \\
\hline
\end{tabular}




\section{Table 3.}

Estimated results of $\Delta p_{i, t}=\alpha+\beta_{i} F_{i, t}+\gamma_{i} T_{i, t}+\varepsilon_{i, t}$.

This table reports the estimation results for Eq. (10). Panel A shows the results for the large-size portfolio, portfolio 1, whilst Panel B reports results for the small-size portfolio, portfolio 2. OLS Fundamental \& Momentum indicates OLSFT model in Eq.s (10). $\mathrm{R}^{2}$ and Adj $\mathrm{R}^{2}$ report the $\mathrm{R}^{2}$ and the adjusted $\mathrm{R}^{2}$ of the regression models. Variable $x$ is earnings divided by the beginning-of-period market value of equity; variable $\Delta q$ is change in profitability; capital investment, variable $\Delta b$, is the change in the book value of equity relative to the prior month; change in growth opportunity, $\Delta g$, is the change in the median analyst forecast of the long-term growth rate; $\Delta d$ is the change in the discount rate (10-year US Treasury bond yield) over the return period. $T_{1 M, i, t}$, $T_{3 M, i, t}, T_{6 M, i, t}, T_{9 M, i, t}$ and $T_{12 M, i, t}$ are the lagged returns of portfolio $i$, lagged by 1, 3, 6, 9 and 12 months, respectively. The sample consists of 130,032 firm-month observations over the period 1999-2012.

$*$, **, *** denote significance at the 10,5 and $1 \%$ level of significance, respectively.

\begin{tabular}{|c|c|c|c|c|c|c|c|}
\hline \multicolumn{4}{|c|}{ Panel A } & \multicolumn{4}{|l|}{ Panel B } \\
\hline \multicolumn{4}{|c|}{ OLS Fundamental \& Momentum } & \multicolumn{4}{|c|}{ OLS Fundamental \& Momentum } \\
\hline Variable & Estimated Coeff & t-stat & p-value & Variable & Estimated Coeff & t-stat & p-value \\
\hline$x$ & $0.393 * * *$ & 11.14 & 0.000 & $X$ & $0.106^{* * *}$ & 5.87 & 0.000 \\
\hline$\Delta q$ & -0.023 & -0.29 & 0.769 & $\Delta q$ & $0.205^{* * *}$ & 3.54 & 0.001 \\
\hline$\Delta b$ & $0.544 * * *$ & 5.82 & 0.000 & $\Delta b$ & $0.313^{*}$ & 1.74 & 0.084 \\
\hline$\Delta g$ & $1.571 * * *$ & 4.49 & 0.000 & $\Delta g$ & $0.428 * * *$ & 5.25 & 0.000 \\
\hline$\Delta r$ & $-0.809 * * *$ & -6.95 & 0.000 & $\Delta r$ & $-1.204 * * *$ & -11.27 & 0.000 \\
\hline$T_{1 M}$ & $-0.164 * * *$ & -3.17 & 0.002 & $T_{1 M}$ & $-0.156 * * *$ & -3.70 & 0.000 \\
\hline$T_{3 M}$ & $0.110 * * *$ & 2.81 & 0.006 & $T_{3 M}$ & $0.073 * *$ & 1.99 & 0.049 \\
\hline$T_{6 M}$ & $-0.134 * * *$ & -3.54 & 0.001 & $T_{6 M}$ & -0.017 & -0.51 & 0.611 \\
\hline$T_{9 M}$ & $-0.096 * * *$ & -2.94 & 0.004 & $T_{9 M}$ & $-0.073 * *$ & -2.24 & 0.026 \\
\hline$T_{12 M}$ & $-0.064 * *$ & -2.03 & 0.044 & $T_{12 M}$ & $-0.062 * *$ & -2.02 & 0.045 \\
\hline constant & $-0.026 * * *$ & -11.14 & 0.000 & constant & 0.000 & 0.15 & 0.879 \\
\hline $\mathrm{R}^{2}$ & 0.782 & & & $\mathrm{R}^{2}$ & 0.796 & & \\
\hline Adj $R^{2}$ & 0.767 & & & Adj $R^{2}$ & 0.782 & & \\
\hline
\end{tabular}




\section{Table 4.}

Estimated results of the state space model.

This table reports the estimation results from the state space model (represented in Eqs (6)-(7)) for explaining monthly stock price movements of all sample stocks in the Russell 3000 index. The sample period used is from January 1999 to December 2012. Panel A shows the results for the large-size portfolio whilst Panel B reports results for the small-size portfolio. Panel $\mathrm{C}$ shows the results for the model specification with only the inclusion of the latent factor, Z. Panel A and B include the estimated results of Eq.s (6) and Panel C includes the estimate result of Eq.s (7). OLS Fundamental \& Momentum indicates OLSFT model in Eq.s (10). Adj $\mathrm{R}^{2}$ rows reports the adjusted $\mathrm{R}^{2}$ equivalent for the OLSFT model. Variable $Z$ is the unobserved factor that is shared by the both portfolios, extracted from the state space model; variable $x$ is earnings divided by the beginning-of-period market value of equity; variable $\Delta q$ is the change in profitability; capital investment, variable $\Delta b$, is the change in the book value of equity relative to the prior month; change in growth opportunity, $\Delta g$, is the change in the median analyst forecast of the long-term growth rate; $\Delta d$ is the change in discount rate (10-year US Treasury bond yield) over the return period. $T_{1 M, i, t}, T_{3 M, i, t}, T_{6 M, i, t}, T_{9 M, i, t}$ and $T_{12 M, i, t}$ are the lagged returns of portfolio $i$, lagged by 1, 3, 6, 9 and 12 months, respectively. The sample consists of 130,032 firm-month observations over the period 1999-2012. *, **, *** denote significance at the 10, 5 and $1 \%$ level of significance, respectively.

\begin{tabular}{lrrr}
\hline Panel A & & & \\
\hline Variable & Estimated Coeff & \multicolumn{1}{c}{ Z-stat } & p-value \\
\hline$Z$ & $0.006^{* * *}$ & 2.94 & 0.003 \\
$x$ & $0.392^{* * *}$ & 12.75 & 0.000 \\
$\Delta q$ & 0.001 & 0.01 & 0.988 \\
$\Delta b$ & $0.449^{* * *}$ & 5.98 & 0.000 \\
$\Delta g$ & $1.151^{* * *}$ & 4.29 & 0.000 \\
$\Delta r$ & $-0.781^{* * *}$ & -6.99 & 0.000 \\
$T_{1 M}$ & $-0.113^{* *}$ & -2.48 & 0.013 \\
$T_{3 M}$ & $0.108^{* * *}$ & 3.04 & 0.002 \\
$T_{6 M}$ & $-0.157^{* * *}$ & -4.90 & 0.000 \\
$T_{9 M}$ & $-0.067 * *$ & -2.37 & 0.018 \\
$T_{12 M}$ & $-0.067 * *$ & -2.48 & 0.013 \\
constant & $-0.025^{* * *}$ & -12.39 & 0.000 \\
\hline
\end{tabular}

Adj $\mathrm{R}^{2} \quad 0.7674$

\begin{tabular}{lrrr} 
Panel B & & & \\
\hline Variable & Estimated Coeff & Z-stat & p-value \\
\hline$Z$ & $0.009^{* * *}$ & 2.94 & 0.003 \\
$x$ & $0.115^{* * *}$ & 7.41 & 0.000 \\
$\Delta q$ & $0.224^{* * *}$ & 4.91 & 0.000 \\
$\Delta b$ & $0.233^{*}$ & 1.66 & 0.097 \\
$\Delta g$ & $0.302^{* * *}$ & 4.84 & 0.000 \\
$\Delta r$ & $-1.257^{* * *}$ & -12.86 & 0.000 \\
$T_{1 M}$ & $-0.141^{* * *}$ & -3.42 & 0.001 \\
$T_{3 M}$ & $0.068^{* *}$ & 2.13 & 0.033 \\
$T_{6 M}$ & -0.044 & -1.50 & 0.134 \\
$T_{9 M}$ & $-0.065^{* *}$ & -2.38 & 0.017 \\
$T_{12 M}$ & $-0.056^{* *}$ & -2.14 & 0.032 \\
constant & 0.001 & 0.70 & 0.486 \\
\hline
\end{tabular}

Panel C

\begin{tabular}{llll}
\hline$Z$ & -0.136 & -1.32 & 0.187 \\
\hline
\end{tabular}


Table 5.

Robustness check with quartile portfolios.

This table reports the estimation results from the OLS model for quartile portfolios in explaining monthly stock price movements of all sample stocks in the Russell 3000 index. The sample period used is from January 1999 to December 2012. Panel A shows the results for the first quartile portfolio, Panel B reports results for the second quartile portfolio, Panel C reports results for the third quartile portfolio and Panel D reports results for the last quartile portfolio. Variable $x$ is earnings divided by the beginning-of-period market value of equity; variable $\Delta q$ is profitability change; capital investment, variable $\Delta b$, is the change in the book value of equity relative to the prior month; growth opportunity change, $\Delta g$, is the change in the median analyst forecast of the long-term growth rate; $\Delta d$ is the discount rate (10-year US Treasury bond yield) change over the return period. $T_{1 M, i, t}, T_{3 M, i, t}, T_{6 M, i, t}, T_{9 M, i, t}$ and $T_{12 M, i, t}$ are the lagged returns of the portfolio $i$, lagged by 1, 3, 6, 9 and 12 months, respectively. The sample consists of 130,032 firm-month observations over the period 1999-2012.

$*, * *, * * *$ denote significance at the 10,5 and $1 \%$ level of significance, respectively.

\begin{tabular}{|c|c|c|c|c|c|c|c|}
\hline Panel 1 & Portfolio 1 & & & Panel 2 & Portfolio 2 & & \\
\hline Variable & Estimate Coeff & t-stat & p-value & Variable & Estimate Coeff & t-stat & p-value \\
\hline$x$ & $0.3958^{* * *}$ & 13.14 & 0.0000 & $x$ & $0.1195^{* * *}$ & 5.98 & 0.0000 \\
\hline$d q$ & $0.1170^{* *}$ & 2.15 & 0.0330 & $d q$ & 0.0302 & 0.87 & 0.3840 \\
\hline$d b$ & $0.2590 * * *$ & 4.17 & 0.0000 & $d b$ & $0.1786^{* * *}$ & 2.85 & 0.0050 \\
\hline$d g$ & 0.0257 & 0.09 & 0.9290 & $d g$ & $0.1867 * * *$ & 4.68 & 0.0000 \\
\hline$d r$ & -0.0233 & -0.23 & 0.8190 & $d r$ & $0.4758^{* * *}$ & 3.25 & 0.0010 \\
\hline$T_{1 M}$ & -0.0924 & -1.64 & 0.1030 & $T_{1 M}$ & 0.0536 & 0.55 & 0.5810 \\
\hline$T_{3 M}$ & 0.0076 & 0.19 & 0.8520 & $T_{3 M}$ & $-0.2996 * * *$ & -4.12 & 0.0000 \\
\hline$T_{6 M}$ & $-0.1075^{* * *}$ & -3.00 & 0.0030 & $T_{6 M}$ & -0.0297 & -0.47 & 0.6390 \\
\hline$T_{9 M}$ & $-0.0644 *$ & -1.88 & 0.0620 & $T_{9 M}$ & 0.0609 & 1.04 & 0.3020 \\
\hline$T_{12 M}$ & -0.0237 & -0.77 & 0.4420 & $T_{12 M}$ & 0.0713 & 1.32 & 0.1900 \\
\hline costant & $-0.0249 * * *$ & -12.44 & 0.0000 & costant & 0.0012 & 0.85 & 0.3980 \\
\hline $\mathrm{R}^{2}$ & 0.7191 & & & $\mathrm{R}^{2}$ & 0.4112 & & \\
\hline Adj $R^{2}$ & 0.6998 & & & Adj $R^{2}$ & 0.3706 & & \\
\hline Panel 3 & & Portfolio 3 & & Panel 4 & Portfolio 4 & & \\
\hline Variable & Estimate Coeff & t-stat & p-value & Variable & Estimate Coeff & t-stat & p-value \\
\hline$x$ & $0.0947 * * *$ & 3.4800 & 0.0010 & $x$ & $0.0688^{* * *}$ & 5.38 & 0.0000 \\
\hline$d q$ & 0.0405 & 0.63 & 0.5320 & $d q$ & $0.2328 * * *$ & 3.32 & 0.0010 \\
\hline$d b$ & -0.0600 & -0.48 & 0.6320 & $d b$ & 0.1014 & 0.55 & 0.5830 \\
\hline$d g$ & 0.0429 & 1.25 & 0.2140 & $d g$ & $0.0566 * * *$ & 3.77 & 0.0000 \\
\hline$d r$ & 0.3365 & 1.63 & 0.1050 & $d r$ & 0.3048 & 1.60 & 0.1110 \\
\hline$T_{1 M}$ & 0.1532 & 1.19 & 0.2340 & $T_{1 M}$ & 0.0178 & 0.16 & 0.8730 \\
\hline$T_{3 M}$ & -0.1327 & -1.61 & 0.1100 & $T_{3 M}$ & -0.0905 & -1.17 & 0.2430 \\
\hline$T_{6 M}$ & -0.0412 & -0.55 & 0.5850 & $T_{6 M}$ & $-0.2132 * * *$ & -3.05 & 0.0030 \\
\hline$T_{9 M}$ & 0.0298 & 0.44 & 0.6640 & $T_{9 M}$ & -0.0500 & -0.76 & 0.4500 \\
\hline$T_{12 M}$ & 0.0521 & 0.81 & 0.4210 & $T_{12 M}$ & 0.0847 & 1.30 & 0.1970 \\
\hline costant & $0.0045^{* *}$ & 2.16 & 0.0320 & costant & $0.0125 * * *$ & 4.27 & 0.0000 \\
\hline $\mathrm{R}^{2}$ & 0.1418 & & & $\mathrm{R}^{2}$ & 0.3269 & & \\
\hline Adj $R^{2}$ & 0.0826 & & & Adj $R^{2}$ & 0.2805 & & \\
\hline
\end{tabular}




\section{Appendix.}

\section{Appendix 1. Descriptive Statistics of the data in Chen and Zhang (2007)}

Panel A1: Descriptive statistics of the pooled sample

\begin{tabular}{lrrrrrrr}
\hline Portfolio Total & Mean & Median & Std dev & \multicolumn{1}{c}{ Min } & 1st quartile & 3rd quartile & Max \\
\hline Portfolio Return & 0.15 & 0.10 & 0.43 & -0.78 & -0.12 & 0.35 & 2.73 \\
Earnings yield (x) & 0.06 & 0.07 & 0.08 & -1.39 & 0.04 & 0.09 & 0.49 \\
Profitability change (dq) (\%) & -1.55 & -0.01 & 14.53 & -143.20 & -5.61 & 3.14 & 149.47 \\
Capital investmnt (db) (\%) & 0.13 & 0.10 & 0.27 & -0.91 & 0.2 & 0.19 & 4.40 \\
Growth opportunity change (dg) (\%) & -0.53 & -0.09 & 3.74 & -55.00 & -1.60 & 0.74 & 47.00 \\
Discount rate change (dr) (\%) & -0.29 & -0.51 & 1.18 & -4.34 & -1.04 & 0.61 & 3.18 \\
B/M ratio & 0.59 & 0.53 & 0.35 & 0.01 & 0.34 & 0.76 & 4.43 \\
\hline
\end{tabular}

Panel A2: Correlation matrix of the total sample

\begin{tabular}{lccccc}
\hline Correlation Matrix & $\mathrm{R}$ & $\mathrm{x}$ & $\mathrm{dq}$ & $\mathrm{db}$ & $\mathrm{dg}$ \\
\hline Earnings yield (x) & 0.29 & & & & \\
Profitability change (dq) (\%) & 0.29 & 0.45 & & & \\
Capital investmnt (db) (\%) & 0.24 & 0.33 & 0.26 & & \\
Growth opportunity change (dg) (\%) & 0.23 & 0.09 & 0.16 & 0.07 & \\
Discount rate change (dr) (\%) & -0.13 & 0.00 & 0.05 & 0.00 & 0.02 \\
\hline
\end{tabular}

Note that Chen and Zhang (2007) use annual data while we use monthly data. Also, they collect the annual stock return from 2 days after the year $t-1$ earnings announcement to one day after the year $t$ earnings announcement. 
Appendix 2. Conditional Variance of Equation (7) $Z_{t}=\rho Z_{t-1}+\sqrt{1-\rho^{2}} \omega_{t}$

$$
\begin{aligned}
& Z_{t}=\rho\left(\rho Z_{t-2}+\sqrt{1-\rho^{2}} \omega_{t-1}\right)+\sqrt{1-\rho^{2}} \omega_{t} \\
& Z_{t}=\rho\left(\rho\left(\rho Z_{t-3}+\sqrt{1-\rho^{2}} \omega_{t-2}\right)+\sqrt{1-\rho^{2}} \omega_{t-1}\right)+\sqrt{1-\rho^{2}} \omega_{t} \\
& \ldots \\
& Z_{t}=\rho^{t} Z_{0}+\sqrt{1-\rho^{2}} \omega_{t}+\rho \sqrt{1-\rho^{2}} \omega_{t-1}+\rho^{2} \sqrt{1-\rho^{2}} \omega_{t-2}+\cdots+\rho^{t} \sqrt{1-\rho^{2}} \omega_{0}
\end{aligned}
$$

Therefore, we have,

$$
Z_{t}=\rho^{t} Z_{0}+\sum_{i=0}^{t} \rho^{i} \sqrt{1-\rho^{2}} \omega_{t-i}
$$

Since $\omega \sim$ i.i.d. $(0,1)$,

$$
\begin{aligned}
& \operatorname{Var}\left(Z_{t}\right)=E\left[\left(Z_{t}-E\left(Z_{t}\right)\right)^{2}\right]=E\left[\left(\sum_{i=0}^{t} \rho^{i} \sqrt{1-\rho^{2}} \omega_{t-i}\right)^{2}\right]=\left(1-\rho^{2}\right) \sum_{i=1}^{t} \rho^{2 i} \omega_{t-1}^{2} \\
& =\left(1-\rho^{2}\right)\left(\omega_{t}^{2}+\rho^{1} \omega_{t-1}^{2}+\rho^{2} \omega_{t-2}^{2}+\cdots \rho^{t} \omega_{0}^{2}\right)
\end{aligned}
$$

$\lim _{t \rightarrow \infty} \operatorname{Var}\left(Z_{t}\right)=\left(1-\rho^{2}\right) \frac{1}{1-\rho^{2}}=1$ 